\title{
Social Inclusion Through Sport for Women Experiencing Homelessness
}

\section{Jenna Richards}

Western University, Canada

\author{
Abe Oudshoorn \\ Western University, Canada \\ Laura Misener \\ Western University, Canada
}

\begin{abstract}
Background: People experiencing homelessness have been described as one of the most socially excluded groups, particularly homeless women. Exploring the barriers and facilitators of social inclusion for women experiencing homelessness, in particular their experience with sports-based activities, may identify key criteria to improve and facilitate their access to community activities and result in opportunities for increased inclusion.

Methods: Qualitative thematic analysis was used to explore women's homelessness, social inclusion, and their interest and engagement in sportbased activities. In a mid-sized city in Canada, data was collected using semistructured interviews with eleven women residing in a shelter. The data were analyzed for themes relating to the research questions.

Findings: Four corresponding themes were derived from the interviews: (a) poverty is the main source of social exclusion, (b) housing is not necessarily a prerequisite for social inclusion, (c) women play sports too; it's not just for men, and (d) Purposeful rather than passive recruitment boosts inclusion. These themes represent the barriers and facilitators of social inclusion that the participants experienced, as well as their experiences and interests in sports.

Conclusion: The findings revealed that while women who are experiencing homelessness may be interested in participating in sport activities as an opportunity to improve aspects of their social inclusion, they face many barriers in accessing sport activities. The findings of this study may inform organizational and government policy, and future research. Further intersectional research is needed to understand how gendered experiences of homelessness intersect for Indigenous or racialized persons.
\end{abstract}

Key words: homelessness, women, social inclusion, social exclusion, sports, intersectionality.

Corresponding author: Jenna Richards (jrich27@uwo.ca) 


\section{Introduction}

In spite of growth in gross domestic product (GDP) across the developed world, neoliberal policies continue to shift resources to a shrinking segment of the population while homelessness continues to grow (Gaetz et al., 2016). With the coinciding disinvestment in the welfare state and rise in neoliberalism in the 1980s, the Canadian government weakened investments in social and health supports and affordable housing (Gaetz et al., 2016). Consequently, as estimated in the past few years, 35,000 individuals are suspected of experiencing homelessness every night in Canada (Gaetz et al., 2016).

Historically, people who were visibly homeless were more likely to be single men experiencing chronic homelessness (Gaetz et al., 2016). The visibly homeless are characterized as people who are utilising emergency shelter and/or sleeping outside in public, and are present in statistics related to homelessness (Whitzman, 2010). Despite data showing the growing diverse homeless population, people who are homeless are often still discussed, researched, and resourced as a homogenous group (Wesely \& Wright, 2005). Failing to highlight the unique populations that experience homelessness can result in underserved sub-groups and further exacerbate the structural barriers and discrimination faced by this population.

Women who are homeless are often portrayed with negative stereotypes that perpetuate the classist and sexist hegemonic structures that exist in Canadian society and disregard the actual experiences of women who are homeless. It is found that women who are homeless face higher rates of violence and discrimination, mental health challenges, and are more likely to be incarcerated (Roschelle, 2017; Weiser et al., 2009). Conducting research regarding homelessness that does not address the unique ways certain social locations, such as gender, race, and sexuality, intersect and how different groups may experience and respond to homelessness risks perpetuating stereotypes and exclusion. Compared to men, women who are homeless are more likely to experience 'hidden homelessness' (Whitzman, 2006). This includes individuals who do not have stable housing and also do not use the shelter system or sleep 'rough' in visible locations. This aspect of 'hidden homelessness' makes it challenging to accurately predict the number of women experiencing homelessness, as well to connect and understand their experiences. Furthermore, hidden homelessness can add to women's experiences of social exclusion (Watson, Crawley, \& Kane, 2016).

Participation in community activities, such as sports, is cited as one method towards social inclusion and improved well-being (Kelly, 2011; Seebohm, Gilchrist, \& Morris, 2009). Social inclusion is a multifaceted concept that can be explored on individual, community, and structural levels. On individual and community levels, social inclusion can be characterized as an individual's personal resources and their opportunity to participate in social, cultural, and political activities (Clifton et al., 2013). However, social inclusion is more than including people who are deemed excluded through their lack of participation in the local community. There are other aspects in a person's social environment that can dictate access to services and may have influence over one's choices (Marmont, 2009). In order for social inclusion to be achievable, the sociopolitical and economic systems that perpetuate inequities need to be challenged (Labonte, 2004). Social exclusion does not always occur by choice, but is more often a process that results from institutional structures that isolate individuals from full participation (Everett, 2009). That said, systemic approaches to inclusion have some risk as social inclusion policies have been scrutinized as a potential means to assimilate society (Everett, 2009). When policy fails to explicitly state the value of diversity, it puts the onus on the individual or group to assimilate to mainstream society (Everett, 2009). Therefore, it is vital to understand what social inclusion means to each individual (Le Boutillier \& Croucher, 2010) and how inclusion at a systemic level can be facilitated in an empowering manner. 
Sport programs have the potential to provide many benefits to those who participate, including improved mental and physical well-being, personal development, and community integration (Doll-Tepper, Koenen, \& Bailey, 2017). However, women also find they are excluded in sports as a consequence of the social construction of sport as a predominantly male domain that often serves to reinforce gender roles (Kay \& Jeanes, 2008). These gender expectations can be isolating to individuals that do not conform to the heteronormative narrative often present in organized sports (Wellard, 2006). As a result, certain groups may be excluded from accessing the potential benefits of participating in sport and physical activities. In order to enact equal participation across genders, a focus on promoting sport that is not constructed along gendered ideologies has the potential to benefit women (Kelly, 2011). Sport activities geared specifically towards women experiencing homelessness may offer new opportunities for their participation and social inclusion, if they account for the gendered nature and preferences in sport participation.

\section{Literature Review}

\section{Social Inclusion, Homelessness, and Poverty}

People experiencing homelessness and living in poverty may experience severe social exclusion that moves beyond their lack of fundamental material well-being (Watson et al., 2016). Watson and colleagues (2016) explored the social exclusion of people who are homeless. The participants cited that their health behaviours, including lack of nutrition and use of illicit drugs, were affected by their lack of social supports and inadequate social environment. Participants described their social exclusion in relation to the inadequate social supports, the necessity of proper housing, and the insufficient quality of shelters. A study by Tsai, Mares, and Rosenheck (2012) found that even with housing, social exclusion remains a significant issue with previously homeless individuals. The researchers did not find a statistically significant difference in the participants' social inclusion after they were housed for a year (Tsai et al., 2012). Similarly, a study by Sylvestre et al. (2018) found that when participants $(N=64)$ with precarious housing histories were housed, it resulted in isolation for some and put them at risk for re-entering homelessness because their need for support went unrecognized (Sylvestre et al., 2018). The researchers recommend conducting further research into specific interventions that could specifically target formerly homeless peoples' sense of social inclusion.

\section{Social Inclusion and Sport}

Internationally, sport is being recognized as a potential means to promote social inclusion (Bloyce, Smith, Mead, \& Morris, 2008; Kelly, 2011). In a study by Kelly (2011), a youth sports program was found to be beneficial for the participants' social inclusion and integration in community. However, research has also found that social exclusion occurs within and from sports, related to factors such as gender, ethnicity, income, disability, and sexuality (Goodwin \& Peers, 2011). Kingsley and Spencer-Cavaliere (2015) aimed to understand experiences of sport from young people who were living with lower incomes. Although the costs of participation in the sports were supplemented through fee assistance programs, at the conclusion of the study all of the participants in this study opted to no longer participate in the sports program. While this decision could be read as a choice by participants, it highlights the importance of considering the social construct of sport itself which is often built upon a model of white, middleclass norms that can result in forced exclusion and/or self-exclusion (Spaaij, Magee, \& Jeanes, 2014).

In a study that examined the experiences of people who participated in the Homeless World Cup, researchers found that the participants on a predominantly male team developed a sense 
of pride and belonging, and re-engagement in the broader community through stable housing, employment, and educational opportunities (Sherry, 2010). While sport has been shown as a compelling engagement tool for marginalized people, sports, particularly traditional model of white, privileged, male sports, alone cannot effect change, and a shift in the broader societal framework is required. Furthermore, the researchers assert that sport programs cannot be assumed inclusive to all. Similarly, Van Hout and Phelan's (2014) study focused on community reintegration for male offenders through organized sports and physical activity. The authors discussed creating sport programs that have choice, drop-in access, and limited stringent rules to allow for greater inclusion and participation (Van Hout \& Phelan, 2014). Understanding the needs of the participants is therefore required in order to foster social inclusion through sportsbased activities.

\section{Sport, Social Inclusion, and Women}

Traditionally, sport is an area where conventional gender roles are shaped, reinforced, and disputed (Collins \& Kay, 2014). In a 'Positive Futures' sport program, the participants' felt there was a positive effect on their level of social inclusion and community integration, however, women were found to be under-represented (Kelly, 2011). The key stakeholders of the Positive Futures program state that they are committed to engaging young women and having equal participation, however the program is geared towards crime reduction in youth, which is generally male-dominated, further excluding women (Kelly, 2011). Women also find they are excluded in sports as consequence of reinforced gender roles and male dominance (Kay \& Jeanes, 2008). In order to enact equal participation across genders, further understanding the socially constructed nature of sport as vehicle that reinforces gender norms and often excludes women is necessary (Kelly, 2011).

Cortis (2009) conducted a study that explored the access and barriers of sports and sport amenities in culturally diverse women. In focus groups, the participants discussed barriers such as lack of self confidence to participate, lack of access, the need for more culturally sensitive sport programs, as well as more programs that are geared towards women-only (Cortis, 2009). However, it was found that stakeholders did not see the necessity to promote activities to a particular gender or culture - as they perceived their programs to be, by default, inclusionary (Cortis, 2009). While this finding outlines the need for attitudinal and structural changes to be made to promote the activities to women (Cortis, 2009), it also fails to acknowledge the inherent social constructs of sport that exclude women. While addressing macro level initiatives are necessary to approach this issue now, Cortis (2009) recommends combining policy in public health, sports, and social inclusion to devise a program that promotes physical activity and inclusion of women.

\section{Statement of Research Problem and Purpose}

From the literature review, it is evident there is a need to further understand women experiencing homelessness and the challenges they face in regards to social inclusion, including their involvement in sport-based activities as a potential intervention. The intersecting oppression that people experiencing homelessness may face is not well understood in relation to how they perceive and seek social inclusion (Benbow, Forchuk, Gorlick, \& Ward-Griffin, 2015). There needs to be an improved understanding of homeless women's perceptions of social inclusion and barriers to their participation in sporting opportunities, otherwise women may continue to face disproportionately high levels of social exclusion. Therefore, this research study examined how women experiencing homelessness perceive social inclusion in relation to the intersecting oppressions they may experience. There was a focus on social inclusion as developed through traditional sport programs, and women's previous experience in sports and community activities, along with the facilitating factors and barriers to participation in 
community sport programs. Furthermore, the women in this study expressed the necessary changes that need to occur in the community for their social inclusion to thrive. The research questions that guided this study are:

1. How do women who are homeless experience social inclusion?

2. For women experiencing homelessness, what are their perceptions regarding sportsbased activities to improve social inclusion?

\section{Ethical Considerations}

Ethics approval was granted for this research study through the Research Ethics Board (REB approval code 108466) at a University in a mid-sized city in Canada, intentionally unnamed here to help protect the confidentiality and anonymity of the study participants. To ensure an ethical process, a thorough and honest explanation of the research study's purpose was provided to each participant through a letter of information. Confidentiality was assured by assigning each participant a code, and only this code was linked to their interview transcript, in addition with storing each participant's consent in a locked cabinet controlled by the primary researcher. Following the interviews, the participants were advised of the services available on-site at the shelter for mental health support.

\section{Methodology and Theoretical Perspective}

The project design for this study is qualitative description, as the intention for the study is to understand and discover the perspectives of the participants involved (Bradshaw, Atkinson, \& Doody, 2017). The specific theoretical lens is that of intersectionality, which is informed by several theories including feminist theory and critical race theory (Crenshaw, 1991). Feminist theory recognizes women and their lived experience as imperative for social change (Varcoe, 1998), while intersectionality focuses on critically examining the social, historical, cultural, and political implications that perpetuate a system of power-imbalances, social organizations, and injustices (Crenshaw, 1991).

\section{Methods}

\section{Setting}

This study was conducted at a multi-service shelter in a mid-sized city in Canada. This shelter was chosen because community sport activities for the purpose of social inclusion were organized and coordinated by the shelter staff.

\section{Sampling strategy}

Convenience sampling was used to obtain in-depth interviews of women's experiences of social inclusion and sport while experiencing homelessness. In this study, eleven participants constituted the final sample. The sample size was determined when the researchers felt the research questions were being sufficiently answered with valuable information. The inclusion criteria for participation in this study were: people who self-identify as women; who are currently residing at the shelter; who are not participating in the shelter's recreational programs, but who are aware of the shelter's recreational programs; and are aged 18 or over. The exclusion criterion was: people who lack the cognitive capacity to independently provide informed consent.

\section{Data Collection}

Recruitment was designed to address the lack of contact options for persons experiencing 
homelessness, while providing opportunities for potential participants to take time to consider participation. Therefore, posters with information of the study were placed around the women's floor of the shelter as well as the researcher spending time on in-person recruitment in the shelter. In total, the researcher used three separate dates to recruit and interview participants to allow opportunity for a diverse sample of women to be eligible to participate in the study. Data was collected using semi-structured interviews. The interviews were all audio recorded with the participants' permission and transcribed verbatim by the researcher. Fifteen to thirty minutes were spent interviewing each participant. To thank the participants for their time, a twenty-dollar honorarium was provided.

\section{Data Analysis}

To guide the analysis for this research study, feminist researcher Patti Lather's (1993) perspective was utilized. This guided inductive analysis to generate themes from the transcribed interviews. To organize the data and develop themes, a descriptive coding system was developed. Seventeen preliminary code words were generated from listening to the recorded interviews and reading the transcripts. As per Lather (1993), contradictions and feelings of unsettlement within the data remained in the analysis and total consensus was avoided. Seven themes were proposed initially from the analysis then collapsed based on similarity, and thoroughly reviewed to ensure the participants' messages remained evident (Braun \& Clarke, 2014). The researcher examined the themes to avoid any absolutes and any issues of power and privilege present (Lather, 1993). Subsequently, four themes were developed from the analysis.

\section{Findings}

The themes are: (a) Poverty is exclusion; (b) Housing is not (necessarily) a prerequisite for social inclusion; (c) Women play sports too; it's not just for men; and (d) Purposeful rather than passive recruitment boosts inclusion.

\section{Poverty is Exclusion}

The extreme level of poverty experienced by the women in this study is exemplified through their daily lives. Many do not have time for leisurely activities - but are spending their time trying to meet or maintain the basic necessities of living. The women's average day often involves searching for safe and affordable housing, looking for a job, meals, and connecting with services. Furthermore, the income the women receive through social assistance is found to scarcely cover daily expenses. The extreme poverty the women in this study experience is a primary root cause of exclusion.

When prompted about her average day, one woman discussed her daily routine of looking for housing and a job, and the lack of stability that coincides with not being housed:

P4: Um looking for housing, and a job, yeah. Get up, have breakfast, go out, look for a job and look for a place to live...it's a little bit difficult [to find housing], in the price range yeah so...Right now everything is just up in the air so, it's hard to concentrate on that [community activities] when you gotta concentrate on yourself.

Similarly, another woman expressed that her priority is to find housing, then she could consider participating in the community:

P1: How do I spend my free time...right now I'm trying to find an apartment...having an apartment first [would increase my participation in the community]. And then l'd go from there. 
Furthermore, while there are subsidized housing options available in the mid-sized city where the study was conducted, some of the women spoke of the challenges related to receiving and living in subsidized housing. This includes a long waitlist, experiencing harassment in the building, and poor conditions of the buildings.

\author{
P3: (...) The thing is that through here [shelter] (...) they put you on a [subsidized] \\ Housing List, which can be up to a year, year and a half. And then the Housing \\ List...they're all places that if I have a chance of you know [having my children], \\ (...) But um I don't want to have them see me in this situation, but I definitely do \\ not want to have them be, or me, live in a place like down here. I need to be away \\ from the area.
}

From the women's stories, it is apparent that seeking specific opportunities for inclusion is rare in the context of constantly searching for difficult to obtain housing. The intersections of gender, disability, and poverty that the women experience are very apparent in the stories they shared. For many of the women, participating in their community is not their priority as they are trying to survive everyday life through finding shelter, food, and a livable income.

\title{
Housing is Not (Necessarily) a Prerequisite for Social Inclusion
}

In this theme, a sense of identity and membership in the social and physical environment of homelessness is apparent. Homelessness does not define the women, as chronic homelessness becomes normalized, and individuals accept a social role within their community of those who are homeless. This notion challenges some current research that states housing is a prerequisite for social inclusion. Many women participating in this study felt socially included and had a sense of self in relation to others, shaped from their shelter and street life. It should be noted that while some women found inclusion in the context of homelessness, for others, a lack of housing was absolutely seen as a barrier to inclusion.

It is notable that several participants expressed satisfaction with their current level of social inclusion. They described themselves as socially included and felt content within their circle of friends and their level of participation in the community, even if they did not participate in any formalized activities. One woman described herself as socially included while also explaining how she prefers to keep to herself:

P1: Yeah, I guess [I'm happy with my social inclusion]...it's alright. (...) I don't bother with too many people. I've got a few friends and I just keep to myself. I like to be private.

While the women may not appear socially included from society's perspective in terms of engaging in numerous recreational activities or having large social networks, their subjective experience of being socially included challenges 'social inclusion checklists' that deem individuals as socially included or excluded. Objective checklists which determine who is socially included potentially compromises individuality, as inclusion is a highly subjective measure based on one's desires for one's own life.

In the context of their street-involved community, some of the participants found specific roles that were communal in nature and added to a sense of belonging. One woman in particular described her role in the community as helping others navigate homelessness and street life. While she acknowledged her own need to be housed, she voiced her concern of being socially isolated once housed. The notion of housing leading to social inclusion among people who have experienced homelessness needs to be approached with nuance, as obtaining housing does physically move people away from their current sense of community, and some identify closeness with this community as positive. 


\section{Women Play Sports too; it's not just for men}

The impetus for this study was the low participation of women in sport activities for people experiencing homelessness at this particular shelter (removed for anonymity). One possibility was that the women in this population simply were not interested in sports. However, in all the interviews, participants recounted a consistent history of playing sports while growing up. Most of the women stated they really enjoyed playing sports, with many women citing a diversity of sports played throughout their youth. Therefore, this theme reveals the community sport-based program offered by the shelter is not seen as a barrier to their participation. All too often sport programs are aimed at men's participation, negating the important role that sport can play in the lives of women.

While most of the women in this study's experiences of sports occurred during their youth while at school, some women had the opportunity to play sports outside of school. One woman discussed her participation in gymnastics:

P3: I did gymnastics from the time I was 4 until I was 18. And then they asked me to go competitive and my parents said no because they wanted me to continue on with schooling.

Another women discussed how she was able to play organized sports through her previous employer:

P4: I used to play basketball, volleyball, (...) I played baseball in the summers stuff like that yeah. And then when I worked at [coffee chain], we played baseball and (...) I think soccer.

While none of the women interviewed were currently involved in organized sports, several stated they would prefer to be involved in sports activities compared to other community programs. It is evident from these interviews that the women have been playing sports from a young age and would likely have the physical literacy and ability to play sports. Equitable access to sports programs needs to be evaluated on the basis of intersecting identities such as gender, race, and disability. It should be noted that the participants in this study, all Caucasian, may have had differential experience and access to sports compared to other racialized persons or those with childhood experiences that did not include sports activities.

\section{Purposeful rather than passive recruitment boosts inclusion}

In this theme, the ineffectiveness of impersonal recruitment for women into sports programs was explored. At the shelter, there were flyers posted around the building which advertised the sports activities. However, it was revealed from the interviews that this is not an effective way to recruit women to join these activities. Many women described hearing about the sports activities but not knowing any details of the program. A couple of the women described the passiveness of placing advertisements on the wall:

P3: Um probably more advertisement of them I would say [would increase my participation]. Cause like you know you don't see, other than the bulletin board, which you know its easy to pass by them, because they always say the same things, that's always like the same signs have been on there five years ago.

P6: Yeah like you are [aware of the sport activities] but its just one piece of paper you know that might get torn down or something (...) 
From these women's interviews, it is apparent that advertisements posted on a wall tend to be overlooked, perhaps due to the multitude of other posters, or due to the women's transient and unsettled day-to-day lives. Other women described how they have overheard staff discuss the sports program but did not have the information to pursue. According to the women interviewed, the lack of personal knowledge and purposive recruitment regarding the sport activities appears to be a barrier to participate. The absence of women participating in the sports activities organized by the shelter confirms that the current recruitment strategy for women appears to be a barrier for participation.

\section{Discussion}

The findings of this research article are similar to other findings around the exclusionary nature of living in poverty. Other researchers have identified people experiencing material deprivation, such as a lack of housing and lack of income, as being subjected to social exclusion due to barriers to accessing basic human needs (Norman, Pauly, Marks, \& Palazzo, 2015; Watson et al., 2016). For the women in the current study, the time spent trying to meet basic human necessities for living precluded participation in community activities. Finding appropriate housing, food, and a livable income was found to leave no time for the women to participate recreationally in their community. Similarly, in a study by Norman and colleagues (2015), they described the participants' daily commitment of trying to access services that related to their survival - leaving little time or energy to participate in the community. Participation in a community activity was found to be risky as it means potentially not getting a meal, or a place to sleep for the night (Norman, Pauly, Marks, \& Palazzo, 2015).

In this study, a few of the women discussed the lack of safety they felt in the available subsidized housing which precluded them from participating in social and cultural activities. Other researchers have found similar findings, with women opting not to live in specific housing due to fear of their safety and their family's safety (Clough, Draughon, Njie-Carr, Rollins, \& Glass, 2014; Lazarus, Chettiar, Deering, Nabess, \& Shannon, 2011). This finding is an example of the gendered nature of poverty, where women are forced into homelessness due to safety concerns. The United Nations Development Programme found that women are more likely to live in extreme poverty compared to men and face more barriers leaving poverty (Bradshaw, Chant, \& Linneker, 2017; Chant, 2008).

The theme, Housing is not (necessarily) a prerequisite for social inclusion, is similar to other studies where people experiencing homelessness have expressed a sense of identity within their community and are content with their social inclusion (Bell \& Walsh, 2015; Stickley, Hitchcock, \& Bertram, 2005). In this study, many of the women expressed that they were happy with their current level of social inclusion and would not want to formally change anything about their social inclusion, even if they did not participate in any formal community programs. This is contrary to popular belief that people who are homeless are by default socially excluded and feel excluded from society. While these women may not participate in any activities or programs in a traditional sense, their community within the women's shelter may be acting as a place of social inclusion and identity for them. The social roles the women in this study occupy may be a form of survival against chronic homelessness in order to remove themselves from the stigmatizing conditions of mainstream society (Gonyea, \& Melekis, 2017).

However, while some women in this study felt content with their social inclusion, other women described the social exclusion they experienced and the powerlessness they felt. Other researchers have identified similar findings with people experiencing homelessness or poverty being subjected to social exclusion due to structural constraints (Van Straaten et al., 2018; Watson et al., 2016). The structural constraints present in society are a result of an oppressive system that forms power imbalances, creating limited power to advocate for oneself among different marginalized social groups, such as women who are homeless. While it may appear 
these women have choice in their actions and to participate in their community to improve their social inclusion, the concept of choice is not straightforward. The experience of different socioenvironmental factors and normative barriers determine access to services and opportunities, which influence an individual's choice in the first place (Marmont, 2009; Spaaij et al., 2014). Therefore, it is challenging to decipher the difference between self-exclusion and forcedexclusion. Spaaij and colleagues (2014) argue that perceived self-exclusion should not be distinct from an individual's social environment and perceived acceptance, as the greater environmental impact is not clear-cut.

In the theme, Women play sports too; it's not just for men, it is identified how all participants had previous experience playing sports in their youth and many cited they would like to continue to play sports. This theme is stated in an intentionally obvious manner as it may be apparent that women play sports, however it was found that gender stereotypes are still pervasive. Little attention has been paid to women who are homeless and their experience with the already gendered realm of sports participation. Researchers have focused on men who are homeless, and their experiences in sports (Koch, Scherer, \& Holt, 2018; Sherry, 2010), but our study demonstrates the intersection of women's homelessness and their engagement in sport activities. While the women had the desire to participate, the intersection of gender norms within and outside of sport made it more challenging for them to engage in the traditional sports program offered. The absence of sports for women who are homeless may also be entrenched in gender stereotypes that present women as finding inclusion through social activities other than sport (Gentile, Boca, \& Giammusso, 2018). However, this assumption is premised on a traditional male model of sport which starts from a point of excluding female participants due to the social context. The findings from this study show that sports can play an important role in the lives of women, but there is an intersection of barriers within and without sport being experienced by the women. The intersection of barriers for women living in poverty has also been highlighted in community recreation programs. Similar to our study findings, Reid, Frisby, and Ponic, (2002) found that the barriers to participation were related to difficulty accessing the programs due to costs, transportation, lack of childcare, and equipment and clothing required - not because of a disinterest in recreational activities. Given the experience and interest of women experiencing homelessness and living in poverty to participate in sport programs, more work needs to be done on breaking down gendered norms of sport and offering greater opportunities for participation.

Findings related to the theme, Purposeful rather than passive recruitment boosts inclusion, are consistent with findings from other research. Researchers have described how passive recruitment for sports and recreational activities, or 'open-access' for all, does not inherently lead to participation and social inclusion for all groups equally (Collins \& Kay, 2014; Cortis, 2009; Waring, \& Mason, 2010). In this theme, the women described hearing or seeing posters about the sport programs, but generally felt they did not have the knowledge to participate. This further reinforces the typically gendered perceptions about traditional sports and the assumptions that all people would feel included. Similarly, Waring and Mason (2010) looked at a sports program in the UK aimed to improve social inclusion. They found that there was a preconceived assumption among stakeholders that merely opening quality recreational facilities within proximity of neighbourhoods that previously did not have access, would by default, bring the community to participate in the facility thereby improving their social inclusion (Waring \& Mason, 2010). However, as the researchers discuss, no longer excluding individuals does not mean inclusion happens (Waring \& Mason, 2010). The women in our study discussed the lack of purposive recruitment as they mostly just saw the posters about the sport programs or overheard staff discussing the sports. The absence of deliberate recruitment is a barrier for women experiencing homelessness, as people in poverty often experience intersecting areas of oppression (Sadler, Lee, Lim, \& Fullerton, 2010), which can impede an individual's ability or choice to participate. The necessity for women experiencing homelessness to have targeted recruitment is imperative as underserved or oppressed populations are often harder to reach 
due to sociodemographic reasons (Sadler et al., 2010). In order to improve women's participation in sport programs, using a snowball strategy to recruit women experiencing homelessness may improve participation. The snowball strategy would include finding a woman experiencing homelessness who is interested in participating in the sports programs and using their social network to recruit similar individuals to participate. The initial recruits would then invite people from their social networks, thus enabling purposeful contact with otherwise hard-to-reach groups (Sadler et al., 2010). However, critical to this consideration is unpacking the gendered nature of the traditional sports that all too often use sport as the 'hook' for sport for development programs. Alternative inclusive models of sport that break down the inherent barriers in these opportunities should be considered.

\section{Limitations}

In this study, there was a limitation on the diversity of the women interviewed. While the researcher aimed to recruit women from various ethnic backgrounds, the majority of women staying at the shelter at the time of the study were Caucasian. Future studies will need to focus on a diverse population of women to see how the intersections of race, gender, and homelessness impact social inclusion and inclusion in sport-based activities. Furthermore, a limitation of the study was the lack of females of diverse gender identities. With the understanding that gender is a social construct (Winter, 2015), the researcher wanted to include transgender women and other women of minority gender to have their voice present in this research study. However, only cisgender women were recruited into the study.

\section{Conclusion}

The findings from this study have implications for housing policies that address the needs of women who are homeless. For example, participants spoke of the unsafe conditions and locations of some current subsidized housing. This finding emphasizes the necessity for safe housing in varying locations, depending on where individuals feel safe. As well, housing policies that prescribe congregated and scattered-site affordable housing options, particularly focusing on the needs of women, must be considered. The inability for the women in the study to participate in their community because they are spending their days trying to meet basic human needs, such as trying to find safe housing, needs to be highlighted in current and future housing and social assistance policies. Ensuring financial security through policies, such as social assistance increases or a universal basic income, could provide equitable access to the basic human rights of housing, along with potentially increased access to community participation and subsequent social inclusion (Schulz, 2017). This study also has implications on policy at a micro level, for organizations interested in promoting inclusion of women experiencing homelessness. It is valuable to have policies in place to support inclusionary practices, such as personal purposive recruitment for vulnerable or hard to reach populations. As well, organizational policy needs to explicitly outline the inclusion of diverse populations through purposive recruitment.

This study uncovered a deeper understanding of women who are homeless and their understanding and experiences of social inclusion, while highlighting understandings of sport as a potential inclusionary activity. Based on the research questions for this study, the themes Poverty is Exclusion, Housing is Not (Necessarily) a Prerequisite for Social Inclusion, Women Play Sports too; it's not just for men, and Purposeful rather than passive recruitment boosts inclusion emerged from the analysis. The themes from this study reveal the complex nature of social inclusion for women experiencing homelessness. The women shared their stories of exclusion experienced through living in poverty, their social identity in the environment of homelessness, and the powerlessness they felt in their current social position. The women expressed the important role sport has played in their lives, however revealed that a lack of purposeful recruitment was a barrier for participation. The findings from this study highlight the 
unique considerations required to enable social inclusion for women experiencing homelessness, and the socio-political and organizational policy changes that are required.

\section{References}

Benbow, S., Forchuk, C., Gorlick, C., \& Ward-Griffin, C. (2015). Social exclusion and health: The development of nursing knowledge. Canadian Journal of Nursing Research, 47(3), 56-72. Retrieved from http://journals.sagepub.com. proxy1.lib.uwo.ca/home/CJN

Blye, M., \& Walsh, C. A. (2015). Finding a place to belong: The role of social inclusion in the lives of homeless men. The Qualitative Report, 20(12), 1977.

Bloyce, D., Smith, A., Mead, R., \& Morris, J. (2008). Playing the game (plan): A figurational analysis of organizational change in sports development in England. European Sport Management Quarterly, 8(4), 359-378. doi:10.1080/16184740802461637

Bradshaw, C., Atkinson, S., \& Doody, O. (2017). Employing a qualitative description approach in health care research. Global Qualitative Nursing Research, 4, 2333393617742282. doi:10.1177/2333393617742282

Bradshaw, S., Chant, S., \& Linneker, B. (2017). Gender and poverty: What we know, don't know, and need to know for agenda 2030. Gender, Place \& Culture, 24(12), 16671688. doi:10.1080/0966369X.2017.1395821

Braun, V., \& Clarke, V. (2014). What can "thematic analysis" offer health and wellbeing researchers? International Journal of Qualitative Studies on Health and Well-being, $9,26152$.

Chant, S. (2008). The 'Feminisation of poverty' and the 'Feminisation' of anti-poverty programmes: Room for revision? Journal of Development Studies, 44(2), 165-197. doi:10.1080/00220380701789810

Clifton, A., Repper, J., Banks, D., \& Remnant, J. (2013). Co-producing social inclusion: The structure/agency conundrum. Journal of Psychiatric \& Mental Health Nursing, 20(6), 514-524. doi:10.1111/j.1365-2850.2012.01953.x

Clough, A., Draughon, J. E., Njie-Carr, V., Rollins, C., \& Glass, N. (2014). 'Having housing made everything else possible': Affordable, safe and stable housing for women survivors of violence. Qualitative Social Work, 13(5), 671-688. doi: $10.1177 / 1473325013503003$

Collins, P., \& Bilge, S. (2016). Intersectionality. Cambridge, UK: Polity Press

Collins, M. F., \& Kay, T. (2014). Sport and social exclusion (Second ed.). Oxfordshire, England; New York: Routledge.

Cortis, N. (2009). Social inclusion and sport: culturally diverse women's perspectives. Australian Journal of Social Issues, 44(1), 91-106. Retrieved from http://www.acoss.org.au

Crenshaw, K. (1991). Mapping the margins: intersectionality, identity politics, and violence against women of color. Stanford Law Review. 43(6), 1241-99. doi:10.2307/1229039

Doll-Tepper, G., Koenen, K., \& Bailey, R. (2017). The Human Capital Model: realising the benefits of sport and physical activity. In Sport, Education and Social Policy: The state of the social sciences of sport, 155-179. https://doi.org/10.4324/978131540486818

Everett, B. (2009, October). Belonging: Social exclusion, social inclusion, personal safety and the experience of mental illness. Retrieved from https://mdsc.ca/ documents/Publications/BELONGING\%20FINAL\%20REPORT.pdf

Gaetz, S., Dej, E., Richter, T., \& Redman, M. (2016). The State of Homelessness in Canada 2016. Toronto: Canadian Observatory on Homelessness Press.

Gentile, A., Boca, S., \& Giammusso, I. (2018). 'You play like a woman!' effects of gender stereotype threat on women's performance in physical and sport activities: A meta- 
analysis. Psychology of Sport \& Exercise, 39, 95-103. doi:10.1016/j.psychsport.2018.07.013

Gonyea, J. G., \& Melekis, K. (2017). Older homeless women's identity negotiation: Agency, resistance, and the construction of a valued self. The Sociological Review, 65(1), 6782. doi:10.1111/1467-954X.12369

Goodwin, D. \& Peers, D. (2011). Disability, sport and inclusion. In S. Dagkas \& K. Armour (Eds.), Inclusion and exclusion through youth sport (pp. 186-202). London: Routledge (PDF) Disability, sport and inclusion. Available from: https://www.researchgate.net/publication/259576501_Disability_sport_and_inclusion

Kay, T., \& Jeanes, R. (2008). Women, sport and gender inequity. In B. Houlihan, Sport and society: A student introduction (2nd ed.) (pp. 130-154). Thousand Oaks, CA: Sage.

Kelly, L. (2011). 'Social inclusion' through sports-based interventions?. Critical Social Policy, 31(1), 126-150. doi:10.1177/0261018310385442

Kingsley, B. C., \& Spencer-Cavaliere, N. (2015). The exclusionary practices of youth sport. Social Inclusion, 3(3), 24-38. doi:10.17645/si.v3i3.136

Klitzing, S. W. (2004). Women living in a homeless shelter: Stress, coping and leisure. Journal of Leisure Research, 36(4), 483-512. doi:10.1080/00222216.2004.11950033

Koch, J., Scherer, J., \& Holt, N. (2018). Slap shot! sport, masculinities, and homelessness in the downtown core of a divided western Canadian inner city. Journal of Sport \& Social Issues, 42(4), 270-294. doi:10.1177/0193723518773280

Labonte, R. (2004). Social inclusion/exclusion: Dancing the dialectic. Health Promotion International, 19(1), 115-121. doi:10.1093/heapro/dah112

Lather, P. (1993). Fertile obsession: Validity after poststructuralism. The Sociological Quarterly, 34(4), 673-693. doi:10.1111/j.1533-8525.1993.tb00112.x

Lazarus, L., Chettiar, J., Deering, K., Nabess, R., \& Shannon, K. (2011). Risky health environments: Women sex workers' struggles to find safe, secure and nonexploitative housing in canada's poorest postal code. Social Science \& Medicine, 73(11), 1600-1607. doi:10.1016/j.socscimed.2011.09.015

Marmont, S. M. (2009). Closing the health gap in a generation: The work of the commission on social determinants of health and its recommendations. Global Health Promotion, 16(1), 23-27. doi:10.1177/1757975909103742

Norman, T. L., Pauly, B., Marks, H., \& Palazzo, D. (2015). Taking a leap of faith: Meaningful participation of people with experiences of homelessness in solutions to address homelessness. Journal of Social Inclusion, 6(2), 19-35.

Sadler, G. R., Lee, H., Lim, R. S., \& Fullerton, J. (2010). Recruitment of hard-to-reach population subgroups via adaptations of the snowball sampling strategy. Nursing \& Health Sciences, 12(3), 369-374. doi:10.1111/j.1442-2018.2010.00541.x

Sherry, E. (2010). (Re)engaging marginalized groups through sport: The homeless world cup. International Review for the Sociology of Sport, 45(1), 59-71. doi:10.1177/1012690209356988

Spaaij, R., Magee, J., \& Jeanes, R. (2014). Sport and social exclusion in global society. New York, NY: Routledge

Stickley, T., Hitchcock, R., \& Bertram, G. (2005). Social inclusion or social control? Homelessness and mental health. Mental Health Practice, 8(9), 26-30.

Sylvestre, J., Klodawsky, F., Gogosis, E., Ecker, J., Polillo, A., Czechowski, K., . . Hwang, S. (2018). Perceptions of housing and shelter among people with histories of unstable housing in three cities in canada: A qualitative study. American Journal of Community Psychology, 61(3-4), 445-458. doi:10.1002/ajcp.12243

Tsai, J., Mares, A. S., \& Rosenheck, R. A. (2012). Does housing chronically homeless adults lead to social integration? Psychiatric Services, 63(5), 427-434. Retrieved from https://www.lib.uwo.ca/cgi-bin/ezpauthn.cgi?url=http:// search.proquest.com/docview/1370734175?accountid=15115

Van Hout, M., \& Phelan, D. (2014). A grounded theory of fitness training and sports participation in young adult male offenders. Journal of Sport \& Social Issues, 38(2), 
124-147. doi:10.1177/0193723513520012

Van Straaten, B., Rodenburg, G., Van der Laan, J., Boersma, S. N., Wolf, Judith R. L. M, \& Van de Mheen, D. (2018). Changes in social exclusion indicators and psychological distress among homeless people over a 2.5-year period. Social Indicators Research, 135(1), 291-311. doi:10.1007/s11205-016-1486-z

Varcoe, S. T. C. (1998). the tyranny of feminist methodology in women's health research. Health Care for Women International, 19(6), 481-493. doi:10.1080/073993398246052

Waring, A., \& Mason, C. (2010). Opening doors: Promoting social inclusion through increased sports opportunities. Sport in Society, 13(3), 517-529. doi:10.1080/17430431003588192

Watson, J., Crawley, J., \& Kane, D. (2016). Social exclusion, health and hidden homelessness. Public Health, 139, 96-102. doi: http://dx.doi.org.proxy1.lib.uwo.ca/10.1016/j.puhe.2016.05.017

Wesely, J., \& Wright, J. (2005). The pertinence of partners. American Behavioral Scientist, 48(8), 1082-1101. doi:10.1177/0002764204274205

Winter, G. F. (2015). Determining gender: A social construct? Community Practitioner, 88(2), 15-17. Retrieved from https://www.lib.uwo.ca/cgi-bin/ezpauthn.cgi?url= http://search.proquest.com/docview/1652466988?accountid=15115

\section{Biographical Notes}

Jenna Richards is a Master of Science Nursing graduate, Western University, Canada.

Abe Oudshoorn is Assistant Professor, Arthur Labatt Family Nursing of Nursing, Western University, Canada.

Laura Misener is Director and Associate Professor, School of Kinesiology, Western University, Canada. 